\title{
Comparison of Infant feeding practices among rural and urban mothers: an observational study
}

\author{
Yadav YS ${ }^{1}$, Yadav $S^{2}$, Rathi $S^{3}$, Dhaneria $\mathbf{M}^{4}$, Poonam Singh ${ }^{5}$ \\ ${ }^{1}$ Dr Yogendra Singh Yadav, Department of Paediatrics, King George's Medical University, Lucknow, Uttar Pradesh. ${ }^{2}$ Dr \\ Sonali Yadav, Department of Obstetrics \& Gynaecology ${ }^{2}$, King George's Medical University, Lucknow, Uttar Pradesh. \\ ${ }^{3}$ Dr Sunil Rathi, Department of Paediatrics, R.D. Gardi Medical College, Ujjain, Madhya Pradesh, India, ${ }^{4}$ Dr Mamta \\ Dhaneria, Department of Paediatrics, R.D. Gardi Medical College, Ujjain, Madhya Pradesh, India, ${ }^{5}$ Dr Poonam Singh, \\ Department of Paediatrics, R.D. Gardi Medical College, Ujjain, Madhya Pradesh, India.
}

Address for correspondence: Dr Yogendra Singh Yadav, E.Mail: dryogendra83@ gmail.com

\begin{abstract}
Background: Infant feeding practices are the major determinants of nutritional status of infants and young children. Present study was undertaken to compare the infant feeding practices of rural and urban mothers and the factors influencing these practices. Methods: An observational study was carried out in department of Paediatrics, C R Gardi hospital (CRGH) associated with R D Gardi Medical College (RDGMC), Ujjain Charitable Trust Hospital (UCTH), a unit of C R Gardi Hospital and urban health centre, associated with R D Gardi Medical College, Ujjain. The present study included a total of 1000 children of which 500 were from rural and 500 from urban background over a period of one year. Information on breast feeding and complementary feeding practices was recorded. Results: In the present study, maximum children in both rural and urban areas were between age group of 12-36 months and majority of children of rural area were males. Significantly higher proportion of rural mothers was labourer, illiterate and belongs to low socioeconomic status groups. Majority of rural mothers discarded colostrums and offered prelacteal feeds to their babies. Significantly higher proportion of urban mothers started early initiation of breast feeding after delivery. Formula milk feeding was commoner in urban babies but bottle feeding was significantly higher in rural babies. Conclusion: Feeding practices are poor in rural area so mothers should receive counselling regarding early initiation, colostrum feeding and appropriate complementary feeding practices. Steps should be taken to improve the educational status of females especially among rural mothers.
\end{abstract}

Keywords: Infant feeding practices, Complementary feeding, Breast feeding.

\section{Introduction}

Appropriate feeding practices are of fundamental importance for the survival, growth, development and nutrition of infants and children everywhere. Amongst various factors that affect the growth of various organs of a child, the most important factor is the nutrition. The optimal duration of exclusive breastfeeding is one of the crucial public health issues that the World Health Organization (WHO) has been keeping under continued review [1]. Continued and frequent breastfeeding protects child health by reducing risk of morbidity and mortality [2]. Maternal factors such as educational status of mother, occupation or work status of mother is associated with infant feeding practices [3]. The

Manuscript received: $27^{\text {th }}$ May 2015

Reviewed: $5^{\text {th }}$ June 2015

Author Corrected: $24^{\text {th }}$ June 2015

Accepted for Publication: $11^{\text {th }}$ July 2015 prevalence of breast feeding in India is high, however there are many traditional practices associated with breast feeding, of which certain undesirable practices like delay in initiating breast feeding, prelacteal feeding and rejection of colostrum need to be discouraged [4]. Optimal Infant and Young Child Feeding practices especially early initiation and exclusive breastfeeding for the first six months of life help ensure young children the best possible start to life. Optimal complementary feeding depends not only on what is fed but also on how, when, where and by whom a child is fed [5]. At 6-11 months of age malnutrition is 43\%, which could be due to inadequate breastfeeding and inappropriate non exclusive breastfeeding and inappropriate complementary foods and then at two 
years this percentage goes upto about $63 \%$ again could be due to inadequate food or inappropriate practices [6]. Mothers with more education are more likely to adopt appropriate health promoting behaviour including feeding habits [7]. Malnutrition has been responsible, directly or indirectly, for $60 \%$ of the 10.9 million deaths annually among children under five. Well over twothirds of these deaths, which are often associated with inappropriate feeding practices, occur during the first year of life [8]. The prevalence of under nutrition is the highest in Madhya Pradesh (55\%) [6]. The prevalence of under-weight children under three years and five years of age are 47 percent, 43 percent respectively. About 55 million, or one-third, of the world's underweight children under age five live in India.

It is clear that infant feeding practices are the major determinants of nutritional status of infants and young children which in turn can be affected by various socio demographic factors. So the present study was designed as an observational study to understand and compare the locally prevalent infant feeding practices and the factors influencing these practices of rural and urban mothers.

\section{Material and Methods}

Study area: The present an observational study was carried out in the department of Paediatrics C R Gardi hospital (CRGH) associated with R D Gardi Medical College (RDGMC), Ujjain Charitable Trust Hospital
(UCTH), a unit of C R Gardi Hospital and urban health centre, associated with R D Gardi Medical College, Ujjain over a period of one year from January 2010 to December 2010.

Inclusion criteria: All the children who were 0 to 3 year of age \&free from significant illness were included in this study.

Exclusion criteria: The children were disqualified from study if they were above 3yrs of age, having congenital anomaly and having systemic illness.

A total 1000 children were taken in two groups, the study population consisted of 500 rural and 500 urban children from birth to 3 years of age were included in this study. A validated semi- structured questionnaire was used. Mothers were informed about study and they were interviewed about feeding practices and socio demographic profile. Informed consent was taken from the parents. The present study was approved by R.D. Gardi Medical College Institutional Ethics Committee.

Analysis of data: The Statistical Package for Social Sciences (SPSS) version 19.0 software was used for analysis of data. Data was the presented in the form of numbers, percentage, mean and standard deviation. Chisquare $\left(\chi^{2}\right)$ test was applied to find out the significant difference between the proportions. A $P$ value of less than 0.05 was considered significant.

\section{Results}

There were total 100 children were included in this study, 500 in each group (rural \& urban) were divided.

Table: 1 Age and gender-wise distribution of study group in rural and urban area

\begin{tabular}{|c|c|c|c|c|c|c|c|c|}
\hline \multirow[t]{3}{*}{$\begin{array}{l}\text { Age group } \\
\text { ( months) }\end{array}$} & \multicolumn{4}{|c|}{$\begin{array}{l}\text { Rural } \\
(n=500)\end{array}$} & \multicolumn{4}{|c|}{$\begin{array}{l}\text { Urban } \\
(n=500)\end{array}$} \\
\hline & \multicolumn{2}{|c|}{ Male } & \multicolumn{2}{|c|}{ Female } & \multicolumn{2}{|c|}{ Male } & \multicolumn{2}{|c|}{ Female } \\
\hline & No & $\%$ & No & $\%$ & No & $\%$ & No & $\%$ \\
\hline $0-6$ & 53 & 18.7 & 37 & 17.1 & 52 & 22.0 & 54 & 20.5 \\
\hline $6-12$ & 66 & 23.3 & 54 & 24.9 & 83 & 35.2 & 110 & 41.7 \\
\hline $12-36$ & 164 & 58.0 & 126 & 58.1 & 101 & 42.8 & 100 & 37.9 \\
\hline Total & 283 & 100 & 217 & 100 & 236 & 100 & 264 & 100 \\
\hline
\end{tabular}

Table 1 shows that Proportion of males in rural group was significantly higher than urban group (56.6\% vs $47.2 \%$; $\mathbf{p = 0 . 0 0 3}$ ). Maximum children were between age group of 12-36 months in both rural and urban groups. 
Table: 2 Socio demographic profile of the study group

\begin{tabular}{|c|c|c|c|c|c|c|}
\hline \multicolumn{2}{|l|}{ Parameter } & \multicolumn{2}{|c|}{$\begin{array}{l}\text { Rural } \\
(n=500)\end{array}$} & \multicolumn{2}{|c|}{$\begin{array}{l}\text { Urban } \\
(n=500)\end{array}$} & \multirow[t]{2}{*}{$\begin{array}{l}\mathbf{P} \\
\text { Value }\end{array}$} \\
\hline & & No & $\%$ & No & $\%$ & \\
\hline \multirow[t]{3}{*}{ 1.Mother's occupation } & House wife & 311 & 62.2 & 376 & 75.2 & \multirow[t]{3}{*}{0.000} \\
\hline & Labourer & 169 & 33.8 & 72 & 14.4 & \\
\hline & Service class & 20 & 4.0 & 52 & 10.4 & \\
\hline \multirow[t]{2}{*}{ 2.Mother's education } & Illiterate & 387 & 77.4 & 146 & 29.2 & \multirow[t]{2}{*}{0.000} \\
\hline & literate & 113 & 22.6 & 354 & 70.8 & \\
\hline \multirow[t]{3}{*}{ 3.Socio economic status } & Lower & 457 & 91.4 & 188 & 37.6 & \multirow[t]{3}{*}{0.000} \\
\hline & Middle & 36 & 7.2 & 276 & 55.2 & \\
\hline & upper & 7 & 1.4 & 36 & 7.2 & \\
\hline
\end{tabular}

Table 2 shows that a significantly higher proportion of women in rural population were labourer $(\mathbf{p}<\mathbf{0 . 0 0 0})$, Literates were more among urban participants with 354 (70.8\%) urban and $113(22.6 \%)$ rural mothers being literates. Majority of rural population belonged to lower socioeconomic status $(91.4 \%),(\mathbf{p}<\mathbf{0 . 0 0 0})$.

Table: 3 Breast feeding practices among study group in rural and urban area.

\begin{tabular}{|c|c|c|c|c|c|c|}
\hline \multicolumn{2}{|l|}{ Variables } & \multicolumn{2}{|c|}{$\begin{array}{c}\text { Rural } \\
(n=500)\end{array}$} & \multicolumn{2}{|c|}{$\begin{array}{c}\text { Urban } \\
(n=500)\end{array}$} & \multirow[t]{2}{*}{$P$ value } \\
\hline & & No & $\%$ & No & $\%$ & \\
\hline \multirow[t]{3}{*}{ 1.Initiation of $\mathrm{BF}$} & $<1 \mathrm{hr}$ & 271 & 54.2 & 359 & 71.8 & \multirow[t]{3}{*}{0.000} \\
\hline & $1 \mathrm{hr}-4 \mathrm{hr}$ & 69 & 13.8 & 74 & 14.8 & \\
\hline & $>1 \mathrm{hr}$ & 160 & 32.0 & 67 & 13.4 & \\
\hline \multirow[t]{2}{*}{ 2.Frequency } & $<8$ times & 120 & 24.0 & 60 & 12.0 & \multirow[t]{2}{*}{0.000} \\
\hline & $\geq 8$ times & 380 & 76.0 & 440 & 88.0 & \\
\hline \multirow[t]{2}{*}{ 4.Prelacteal feed } & Given & 251 & 50.2 & 92 & 18.4 & \multirow[t]{2}{*}{0.000} \\
\hline & Not given & 249 & 49.8 & 408 & 81.6 & \\
\hline \multirow{5}{*}{$\begin{array}{l}\text { 5.Type of pre lacteal } \\
\text { feeds }\end{array}$} & Sugar water & 42 & 16.7 & 15 & 16.3 & \multirow[t]{5}{*}{0.000} \\
\hline & Honey & 33 & 13.2 & 0 & 0 & \\
\hline & Tea & 30 & 12.0 & 11 & 11.9 & \\
\hline & Kadha & 86 & 34.2 & 0 & 0 & \\
\hline & Milk(animal) & 60 & 23.9 & 66 & 71.8 & \\
\hline \multirow[t]{2}{*}{ 6.Colostrum } & Given & 347 & 69.4 & 479 & 95.8 & \multirow[t]{2}{*}{0.000} \\
\hline & Not given & 153 & 30.6 & 21 & 4.2 & \\
\hline \multirow{2}{*}{$\begin{array}{l}\text { 7.Exclusive BF till } 6 \\
\text { months }\end{array}$} & Given & 293 & 58.6 & 370 & 74 & \multirow[t]{2}{*}{0.000} \\
\hline & Not given & 207 & 41.4 & 130 & 26 & \\
\hline
\end{tabular}

Table 3 shows that Initiation of breast feeding was delayed beyond $4 \mathrm{~h}$ by 160 (32\%) rural and 67 (13.4\%) urban mothers. Frequency of breast feeding $\geq 8$ times/day was more prevalent in urban mothers $(88 \%)$ than rural mothers (76\%). Practice of giving prelacteal feeds was more prevalent among 251 (50.2\%) rural as compared with $92(18.4 \%)$ urban mothers; most commonly in the form of kadha $86(34.2 \%)$ by rural mothers and animal milk 66 (71.8\%) by urban mothers. As many as $153(30.6 \%)$ rural and $21(4.2 \%)$ rural mothers discarded the colostrum. Most of the urban mothers had given exclusive breast feeding till 6 months of age. 
Table: 4 Prevalence of bottle feeding and use of commercial formula feed in rural and urban area

\begin{tabular}{|l|l|l|l|l|l|l|}
\hline \multirow{2}{*}{$\begin{array}{l}\text { Feeding } \\
\text { practices }\end{array}$} & \multicolumn{2}{|l|}{ Rural(n=500) } & \multicolumn{2}{l|}{ Urban(n=500) } & \multirow{2}{*}{ P value } \\
\cline { 3 - 7 } & No & \% & No & \% & \\
\hline \multirow{3}{*}{ 1Bottle feeding } & Given & 175 & 35.0 & 97 & 19.4 & \multirow{2}{*}{$\mathbf{0 . 0 0 0}$} \\
\cline { 2 - 7 } & Not given & 325 & 65.0 & 403 & 80.6 & \\
\hline \multirow{2}{*}{ 2.Formula milk } & Given & 10 & 2 & 36 & 7.2 & \multirow{2}{*}{$\mathbf{0 . 0 0 0}$} \\
\cline { 2 - 6 } & Not Given & 490 & 98 & 464 & 92.8 & \\
\hline
\end{tabular}

Table 4 shows that higher proportions of babies in rural areas were bottle fed in comparison to urban areas. Difference was statistically significant (35\% Vs $19.4 \%$; $=0.000$ ). Only $7.2 \%$ among urban population and $2 \%$ of rural population gave their infants commercial formula feeds, $(7.2 \%$ Vs $2 \% ; \mathrm{p}=0.000)$.

Table: 5 Complementary feeding practices in children of rural and urban areas

\begin{tabular}{|c|c|c|c|c|c|c|}
\hline \multicolumn{2}{|c|}{ Complementary feeding practices } & \multicolumn{2}{|c|}{$\operatorname{Rural}(n=419)$} & \multicolumn{2}{|c|}{ Urban $(n=385)$} & \multirow[t]{2}{*}{ P value } \\
\hline & & No & $\%$ & No & $\%$ & \\
\hline \multirow[t]{2}{*}{ 1.Time of introduction } & Appropriate & 311 & 74.2 & 356 & 92.5 & \multirow[t]{2}{*}{0.000} \\
\hline & Delayed & 108 & 25.8 & 29 & 7.5 & \\
\hline \multirow[t]{3}{*}{ 2.Type } & Milk based & 181 & 43.2 & 70 & 18.2 & \multirow[t]{3}{*}{0.000} \\
\hline & Cereal based & 69 & 16.5 & 32 & 8.3 & \\
\hline & Mixed & 169 & 40.3 & 283 & 73.5 & \\
\hline \multirow[t]{2}{*}{ 3. Frequency } & Inappropriate & 50 & 11.9 & 38 & 9.9 & \multirow[t]{2}{*}{0.349} \\
\hline & Appropriate & 369 & 88.1 & 347 & 90.1 & \\
\hline
\end{tabular}

Table: 5 demonstrate comparison between complementary feeding practices of rural and urban population. Significantly higher proportion of rural mothers introduced complementary feeds at a later age than required in comparison to the urban mothers $(25.8 \%$ vs. $7.5 \%$; $\mathbf{p = 0 . 0 0 0})$. In rural area, milk based CF was given in $43.2 \%$ mixed in $40.3 \%$ and cereal based in $16.5 \%$ of the cases. In urban population, most common complementary feed was mixed type (73.5\%), followed by milk based $(18.2 \%)$ and least common was cereal based $(8.3 \%)$. Higher proportion of rural children were given complementary feeds less than recommended age specific appropriate frequency than urban children $(11.9 \%$ vs $9.9 \%$, $\mathrm{p}=0.349)$.

\section{Discussion}

Optimal infant and young child feeding practices are crucial for growth, development and ultimately the survival of infants and young children [9]. Feeding practices include breast feeding and complimentary feeding practices. Several factors like maternal age, education, socio economic status, marital status, breast feeding support and counselling affect the feeding practices [3].

Purpose and benefits of breast feeding and complementary feeding at appropriate time has been stressed all over the world by various health organizations and community-based programs and approaches. In the present study, we have tried to find out and compare the prevalent feeding practices in rural and urban areas in children below 3 years and also to know other socio demographic factors influencing the breast feeding practices. In the present study, the observation was contrary to what was observed in the national survey. Urban area appeared better in all the aspects of breast feeding than rural area. However, breast feeding practices were still suboptimal in both the areas.

Current study observed that proportions of males were significantly higher in the rural population and literacy rate of females in urban group was three times higher than that of rural group. Significantly higher proportion of rural children belonged to lower socio economic status in our study. In the present study, significantly higher proportion of urban mothers initiated breastfeeding within one hour than rural mothers (71.8\%vs54.2\%). Data are quite variable all over India, while NFHS- 3 data show that only $25 \%$ of mothers had initiated breastfeeding within one hour after birth [10]. Several other studies showed prevalence of initiation of breast feeding within one hour was $70 \%$ in Surat [11], 
$61.3 \%$ at Navi Mumbai [4] and 38\% at slums of Bhavnagar city Gujarat [12].

Present study showed that $50.2 \%$ of rural and $18.4 \%$ of urban babies received prelacteal feeds and most prevalent prelacteal feed in rural area was kadha (86\%), while in urban most common prelacteal was animal milk (71.8\%). On the contrary, in various studies prevalence of prelacteal feeds was $50.8 \%$ [13], $40 \%$ [14], 19\% [15]. Probably, a strong custom of sweetening the newborns' mouth prevailing in the entire district can be held responsible for almost same proportion of study participants giving prelacteal feeds to their infants in urban as well as rural study areas.

In the present study colostrum was given to $95.8 \%$ of urban and $69.4 \%$ of rural babies. There is variation in prevalence of giving colostrums countrywide. According to various studies, acceptance of colostrum was $95 \%$ [4], $51.1 \%$ by santhal and $66 \%$ by non santhal mothers, where as $11.8 \%$ of woman gave colostrums to their babies in rural area of Aligarh, UP [16].

In present study practice of giving exclusive breast feeding till 6 months of age was found in $90.2 \%$ of urban and $74.4 \%$ of rural population. It is quite satisfactory as compared with NFHS-3 data and other studies. Studies [17-20] done in various states of India have showed that exclusive breast feeding rate ranged from 23.50 to $69.35 \%$.

In the present study, bottle feeding was practiced by $35.0 \%$ of rural and $19.4 \%$ of urban mothers. Formula milk feeding was done by $2 \%$ of rural and $7.2 \%$ of urban. Previous studies have reported a comparable bottle feeding prevalence of $23 \%$ [21], 14.8\% [22] and $10.2 \%$ [23] and various other studies reported prevalence of commercial formula milk $16 \%$ [23] and $26 \%$ [24].

In present study timely introduction of complementary food was found in $92.5 \%$ of urban and $74.2 \%$ of rural population, which was quite higher than reported by other studies. According to Bhavdekar SB et al [21] $48 \%$ of children timely started complementary food in Bombay slum. Complimentary feeding at 6-9 months of age was reported to be $71.7 \%$ in Kolkata by Roy S et al [17] and 38.7\% in Allahabad [14].

In present study most common complementary food in rural population was milk based preparation (43.2\%), whereas in urban area most common complementary food was mixed type (73.5\%). Taneja DK et al [24] conducted a study to know the feeding practices in rural area of Delhi and their results showed that only $65.1 \%$ of children were given semisolids between 6-9 months.

In present study most of the children in both the groups (88.1\% rural and $90.1 \%$ in urban) were fed with appropriate frequency according to age as per IMNCI Guidelines, which was quite higher than other studies. Sinhababu A et al [23] found that proportion of children between 6-11 months and 12-23 months being fed as age specific appropriate feeding IMNCI guidelines were $15.2 \%$ and $8.7 \%$ respectively.

Higher occurrence of maternal illiteracy and lower socio economic status are also found to be associated with poor feeding practices. Feeding practices have been found to be better in the present study which can be partly explained by the fact that it was a hospital based study and those mothers who approach health care facilities for minor illnesses of their babies may receive counselling regarding immunization and feeding which improves their practices. So more studies are requiring in the future knowing local culture and feeding practices.

\section{Conclusion}

Present study revealed that infant and young child feeding practices are poor in rural as compared to urban area. Higher occurrence of maternal illiteracy and lower socio economic status are also found to be associated with poor feeding practices in rural area, While urban mothers had more favourable practices compared to rural mothers. Steps should be taken to improve the educational status of females especially among rural population. Mothers should receive counselling regarding early initiation, colostrum feeding, frequency, duration of exclusive breast feeding and appropriate complementary feeding practices.

\section{Acknowledgements (If any)}

We are thankful to all mothers of the infants for their cooperation. We are also very grateful to statistician for analysis of data.

\section{Funding: Nil}

Conflict of interest: Nil

Permission from Institutional Research Board (IRB): Yes

\section{References}


1. WHO/UNICEF. Global strategy for infant and young child feeding. Geneva, World Health Organization, 2002.

2. Molbak K, Gottschau A, Aaby P, Hojlyng N, Ingholt L, Silva AP. Prolonged breast feeding, diarrhoeal disease, and survival of children in Guinea-Bissau. BMJ. 1994 May 28; 308 (6941):1403-6.

3. Nath DC, Goswami G. Determinants of breastfeeding patterns in an urban society of India. Human Biology 1997; 69:557-573.

4. Kulkarni RN Anjenayas, Gujar R, breatsfeeding practice in an urban community of Kalambeli, Navi Mumbai Indian J of community med 2004;29 (4):17980 .

5. Pelto G, Levitt E, Thairu L. Improving feeding practices: current patterns, common constraints, and the design of interventions. Food and Nutr Bull 2003; 24(1):45-82.

6. National Family Health Survey - 2. International Institute for Population Sciences. 1998-1999.

7. National guidelines on infant \& young child feeding, Ministry of Women and Child Development, Govt. of India 2006.

8. WHO. Global Strategy for Infant and Young Child Feeding. Geneva: World Health Organization, ISBN 92 41562218.2003.

9. Black RE, Morris SS, Bryce J. Where and why are 10 million children dying every year Lancet 2003; 361: 222634.

10. National Family Health Survey - 3. International Institute for Population Sciences. 2005-2006.

11. Nayak sunil et al, breast feeding practice in urban community of Surat. Nat J of community med 2010; 1(2):111-113.

12. Raval D et al, A study of breastfeeding practices among infants living in slums of Bhavnagar city, Gujrat India. Health line ISSN 2011; 02 (02):78-83.

13. Gupta A, Venkatesh M. Patil, Sharad G. Tenglikar, Srinivas reddy, Vijayanath.V, Breast Feeding Practices Among Mothers In Urban Field Practice Area of M.R.
Medical College, Gulbarga, J Pharmaceut Biomed Sci 2011;04(04):1-3.

14. Kumar D, Goel N, Mittal PC, Misra P. Influence of infant-feeding practices on nutritional status of under five children. Indian Pediatr 2006 May;73(5):417-21.

15. Madhu K, Chowdary S, Masthi R. Breastfeeding practice and Newborn care in rural areas: A descriptive cross sectional study. Indian J of community med 2009; 34 (3):243-246.

16. Bhardwaj N, Hasan, Badrul S.; Zaheer, Mohammad: Breast-Feeding and Weaning Practices- A Rural Study in Uttar Pradesh. The Journal of Family Welfare. March 1991. 39(1) 23-29.

17. Roy S, Dasgupta A, Pal B. Feeding practices of children in an urban slum of Kolkata. Indian J Community Med 2009; 34:362-3.

18. Medhi GK, Mahanta J. Breastfeeding, weaning practices and nutritional status of infants of tea garden workers of Assam. Indian Pediatr ; 2004 Dec;41(12):1277-9.

19. Fazilli A, Bhat IA, Iqbal M, Abid A, Jabeen R. Infant feeding practices of multiparous women attending the antenatal clinic in a tertiary care hospital. Int J Med Public Health 2011; 1:47-50.

20. Bobhate PS, Shrivastava SR. Breastfeeding practices and factors associated with it: A cross sectional study among tribal women in khardi primary health centre, Thane, India. Int J Public Health Res 2012; 2:115-21.

21. Bavdekar SB, Bavdekar MS, Kasla RR, Raghunandana KJ, Joshi SY, Hathi GS. Infant Feeding Practices in Bombay Slums. Indian Pediatr1994 Sep;31(9):1083-7.

22. Kushawaha KP, Mathur GP, Prakash O. Infant feeding practices of peri-urban areas of Gorakhpur. Indian Pediatr 1987 Oct;24(10):899-901.

23. Sinhababu A. Dipta K. Mukhopadhyay, Tanmay K. Panja, Asit B. Saren, Nirmal K. Mandal, and Akhil B. Biswas, Infant and Young Child-feeding Practices in Bankura District, West Bengal, India. J Health Popul Nutr 2010 Jun; 28(3):294-299. 
24. Taneja DK, Renuka saha, Pratibha Dabas, V.P. Gautam, Y. Tripathy,M. Mehra. Astudy of Infant Feeding Practices and the Underlying Factors in a Rural
Area of Delhi. Indian J Community Health 2003; 28(3):2003-7.

\section{How to cite this article?}

Yadav YS, Yadav S, Rathi S, Dhaneria M, Poonam Singh. Comparison of Infant feeding practices among rural and urban mothers: an observational study. Int J Med Res Rev 2015;3(6):547-553. doi: 10.17511/ijmrr.2015.i6.104. 